Cite this: DOI: $10.1039 / c 9 c p 00425 d$

\section{Ionic transport in highly concentrated lithium bis(fluorosulfonyl)amide electrolytes with keto ester solvents: structural implications for ion hopping conduction in liquid electrolytes $\dagger$}

30 Received 23rd January 2019, Accepted 5th February 2019

DOI: $10.1039 /$ c9cp00425d

rsc.li/pccp

\author{
Shinji Kondou, ${ }^{a}$ Morgan L. Thomas, (D) a Toshihiko Mandai, ${ }^{b}$ Kazuhide Ueno, (D) *a \\ Kaoru Dokko (D) and Masayoshi Watanabe (D) ${ }^{a}$
}

Recent studies have suggested that a Li ion hopping or ligand- or anion-exchange mechanism is largely involved in Li ion conduction of highly concentrated liquid electrolytes. To understand the determining factors for the Li ion hopping/exchange dominant conduction in such liquid systems, ionic diffusion behavior and Li ion coordination structures of concentrated liquid electrolytes composed of lithium bis(fluorosulfonyl)amide (Li[FSA]) and keto ester solvents with two carbonyl coordinating sites of increasing intramolecular distance (methyl pyruvate (MP), methyl acetoacetate (MA), and methyl levulinate $(M L))$ were studied. Diffusivity measurements of MP- and MA-based concentrated electrolytes showed faster $\mathrm{Li}$ ion diffusion than the solvent and FSA anion, demonstrating that $\mathrm{Li}$ ion diffusion was dominated by the $\mathrm{Li}$ ion hopping/exchange mechanism. A solvent-bridged, chain-like $\mathrm{Li}$ ion coordination structure and highly aggregated ion pairs (AGGs) or ionic clusters e.g. $\mathrm{Li}_{x}[\mathrm{FSA}]_{y}^{(y-x)-}$ forming in the electrolytes were shown to contribute to $\mathrm{Li}$ ion hopping conduction. By contrast, ML, with greater intramolecular distance between the carbonyl moieties, is more prone to form a bidentate complex with a Li cation, which increased the contribution of the vehicle mechanism to Li ion diffusion even though similar AGGs and ionic clusters were also observed. The clear correlation between the unusual Li ion diffusion and the solvent-bridged, chain-like structure provides an important insight into the design principles for fast $\mathrm{Li}$ ion conducting liquid electrolytes that would enable $\mathrm{Li}$ ion transport decoupled from viscosity-controlled mass transfer processes.

\section{Introduction}

Li ion conducting electrolytes are a key component of lithium vehicles and other energy storage applications, intense research efforts are devoted to novel electrolyte materials with improved thermal and electrochemical stabilities and high ionic conductivity. Of particular importance are fast $\mathrm{Li}$ ion conducting

${ }^{a}$ Department of Chemistry and Biotechnology, Yokohama National University, 79-5 Tokiwadai, Hodogaya-ku, Yokohama 240-8501, Japan. E-mail: ueno-kazuhiderc@ynu.ac.jp; Fax: +81-45-339-3951; Tel: +81-45-339-3951

${ }^{b}$ Department of Chemistry and Biological Science Studies in Chemistry, Iwate

University, Ueda 4-3-5, Morioka, 020-8551, Japan

$\dagger$ Electronic supplementary information (ESI) available: $\mathrm{Li}^{+}$transference number. Details of single crystals at $\mathrm{Li}[\mathrm{FSA}]: \mathrm{MP}=1: 0.5, \mathrm{Li}[\mathrm{FSA}]: \mathrm{MP}=1: 2$, and Li[TFSA $]:$ MA = $1: 0.5$. Raman spectra for MP- and MA-based electrolytes $(1600-$ $\left.1800 \mathrm{~cm}^{-1}\right)$, for solid Li[FSA] and MP-based electrolytes at [MP]/[Li] $=0.5(780-900$ $\mathrm{cm}^{-1}$ ), for FSA anions $\left(720-760 \mathrm{~cm}^{-1}\right)$, and for ML-based electrolytes (700-850

materials for developing high-power and fast-charging battery systems. In this context, superionic, inorganic solid-state electrolytes, wherein ion transport occurs solely by Li ion hopping conduction, have gained much interest since state-of-the-art solid-state electrolytes rival liquid electrolytes in conductivity $\left(10^{-3}-10^{-2} \mathrm{~S} \mathrm{~cm}^{-1}\right)$ and possess single $\mathrm{Li}$ ion conduction behavior (i.e., Li transference number, $t_{\mathrm{Li}} \sim 1$ ). ${ }^{1,2}$ Indeed, a solid-state battery with sulfide-based superionic conductors demonstrated stable cycle performance and very fast chargedischarge operation, even within three minutes. ${ }^{3}$ However, constructing an effective electrolyte/electrode interface remains a critical challenge to the manufacture of large-scale solid-state cells for practical applications.

Highly concentrated liquid electrolytes have also drawn attention as prospective electrolyte materials for high-performance batteries. ${ }^{4}$ Near-saturation salt concentrations result in the scarcity of uncoordinated solvents in the electrolytes, improving the thermal and electrochemical stabilities. ${ }^{5,6}$ Highly concentrated electrolytes also offer promise as electrolyte materials for high energy and power density cells: they enable higher rate 
1 charge-discharge performance of Li-ion batteries and more stable charge-discharge cycling of the metallic Li anode, compared with conventional organic liquid electrolytes. ${ }^{7-12}$

Although the basic assumptions underlying models of the ion transport processes in liquid electrolytes rely predominantly on simple physical diffusion of ions according to the Stokes-Einstein relationship, recent molecular dynamics simulation studies predicted that $\mathrm{Li}$ ion hopping or exchange mechanisms through frequent exchange of solvents and anions

10 with labile $\mathrm{Li}$ ion coordination can contribute to the ionic conduction of highly concentrated electrolytes. ${ }^{13-15}$ Despite low ionic conductivity and high viscosity, stable cycling of $\mathrm{Li}$ and $\mathrm{Na}$ ion batteries with high current density was reported for ionic liquid (IL)-based concentrated electrolytes. The improved capability was considered to be influenced by the increased mass transfer via ion hopping or exchange mechanisms through large ionic aggregates $\left(\mathrm{Li}_{m}{ }^{+} \mathrm{X}_{n}{ }^{-}\right)$present in the IL-based concentrated electrolytes. ${ }^{16-18}$

In our previous work, diffusivity measurements by pulsedfield gradient (PFG-) NMR have shown that Li ions diffuse the fastest among the components (i.e. more rapidly than solvent molecules and anions) in sulfolane (SL)-based highly concentrated electrolytes. ${ }^{19}$ Here we note that another group also reported the fastest diffusion of Li ions in SL-based concentrated electrolytes. ${ }^{20}$ This provides clear experimental evidence to suggest that Li ion hopping or exchange mechanisms make a significant contribution to $\mathrm{Li}$ ion diffusion. This unusual behavior was attributed to a unique Li ion coordination struc-

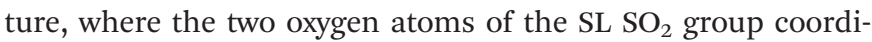
nate to two different $\mathrm{Li}$ cations forming a $\mathrm{SL}-\mathrm{Li}^{+}-\mathrm{SL}$ alternating chain structure. This finding motivated us to further elucidate the determining factors of the hopping/exchange-dominated $\mathrm{Li}$ ion conduction in liquid electrolytes.

Although the requisite molecular design and coordination structure were not understood in detail, we hypothesized that a solvent having multiple coordinating sites, with some degree of geometric/spatial-hinderance of multidentate coordination forms a solvent-bridged, ionic network structure at high salt concentrations, which can give rise to the hopping/exchangedominated $\mathrm{Li}$ ion conduction. In this study, keto ester compounds, methyl pyruvate (MP), methyl acetoacetate (MA), and methyl levulinate (ML), with zero, one or two methylene groups between the two carbonyl groups, respectively, were chosen as the solvents (Fig. 1), and effects of solvent molecular structures on ionic diffusion were studied for highly concentrated electrolytes comprised of these solvents and lithium bis(fluorosulfonyl)amide (Li[FSA]). Li ion diffusion was found to be the fastest in shorter

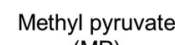
(MP)

$$
\text { Methyl acetoacetate }
$$
(MA)

$$
\text { Methyl levulinate }
$$
(ML)
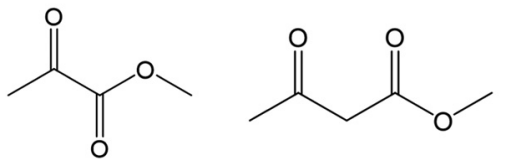

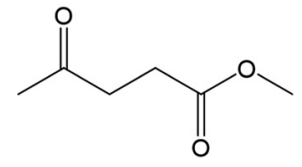

Fig. 1 Chemical structure of keto ester solvents.
MP- and MA-based electrolytes, whereas the highest self-diffusion coefficient was observed for the anion in ML-based electrolytes. To unravel the origin of the different ionic diffusion behavior in the keto ester-based concentrated electrolytes, the coordination structure of the Li ions was studied with single crystal X-ray crystallography and Raman spectroscopy and the correlations between the ionic diffusion behavior and the coordination structure were discussed.

\section{Experimental}

\section{Materials}

Lithium bis(fluorosulfonyl)amide (Li[FSA]) was purchased from Kishida Chemical Co. (Japan) and used as received. Lithium bis(trifluoromethanesulfonyl)amide (Li[TFSA]) was kindly supplied by Solvay Japan. Methyl pyruvate (MP), methyl acetoacetate (MA), and methyl levulinate (ML) were purchased from Tokyo Chemical Industry Co. (Japan) and were dried over molecular sieves (3A) prior to use. The sample electrolytes were prepared by mixing $\mathrm{Li}[\mathrm{FSA}]$ and the solvent at an appropriate ratio in an Ar-filled glove box (VAC, $\left.\left[\mathrm{H}_{2} \mathrm{O}\right]<1 \mathrm{ppm},\left[\mathrm{O}_{2}\right]<1 \mathrm{ppm}\right)$.

\section{Measurements}

The ionic conductivity $(\sigma)$ of samples was determined by the complex impedance method using an impedance analyzer (VMP, Biologic) in the frequency range of $500 \mathrm{kHz}-1 \mathrm{~Hz}$ with a sinusoidal alternating voltage amplitude of $10 \mathrm{mV}$ root-meansquare (rms). A two platinized platinum electrode cell (CG-511B, TOA Electronics) was utilized for the conductivity measurements, and the cell constant was determined using a $0.01 \mathrm{M} \mathrm{KCl}$ aqueous solution at $25{ }^{\circ} \mathrm{C}$ prior to the measurements. The density and viscosity were determined using a viscometer (SVM 3000, Anton Paar), and lithium salt concentration $\left(c_{\mathrm{Li}}\right)$ was determined from the density value at $30{ }^{\circ} \mathrm{C}$ and the molecular weight of the electrolytes.

The glass transition temperature $\left(T_{\mathrm{g}}\right)$ was determined using a differential scanning calorimeter (DSC7020, Hitachi HighTech Science). The samples were hermetically sealed in aluminum pans. The samples were first heated to $60{ }^{\circ} \mathrm{C}$, followed by cooling to $-150{ }^{\circ} \mathrm{C}$, and then reheated from $-150{ }^{\circ} \mathrm{C}$ to $60{ }^{\circ} \mathrm{C}$ at a scan rate of $5{ }^{\circ} \mathrm{C} \mathrm{min}^{-1}$ under a nitrogen atmosphere.

PFG-NMR measurements were carried out to determine the self-diffusion coefficients of solvents (MP, MA, ML), $\mathrm{Li}^{+}$, and $[\mathrm{FSA}]^{-}$using a bipolar pulse-pair longitudinal eddy current delay (BPP-LED) pulse sequence with sinusoidal PFG. ${ }^{21,22} \mathrm{~A}$ JEOL-ECX 400 NMR spectrometer with a $9.4 \mathrm{~T}$ narrow-bore superconducting magnet equipped with a pulsed-field gradient probe and a current amplifier was used for the measurements: the solvents $\left({ }^{1} \mathrm{H}, 399.7 \mathrm{MHz}\right)$, FSA anions $\left({ }^{19} \mathrm{~F}, 376.1 \mathrm{MHz}\right)$, and lithium cations $\left({ }^{7} \mathrm{Li}, 155.3 \mathrm{MHz}\right)$. The sample was inserted into an NMR microtube (BMS-005J Shigemi) to a height of $3 \mathrm{~mm}$ to exclude convection, and the measurements were performed at $30{ }^{\circ} \mathrm{C}$.

Raman spectra were measured using a Raman spectrometer with a $785 \mathrm{~nm}$ laser (NRS-4100, JACSO) and the instrument was calibrated using a polypropylene standard before the 
1 measurements. The spectroscopic resolution was $4.6 \mathrm{~cm}^{-1}$. The samples were sealed in a capillary tube, and their temperature was controlled using a Peltier microscope stage (TS62, INSTEC) with a temperature controller (mk1000, INSTEC).

Density functional theory (DFT) and quantum calculations were performed using the Gaussian 09 program. ${ }^{23}$ The geometries of the complexes of $\mathrm{Li}$ ions and the keto ester solvents were optimized at the B3LYP/6-311+G* level, and vibrational analysis of the optimized structures was further performed at the same level.

Single crystal X-ray structure analysis was performed on a Rigaku XtaLAB PRO diffractometer using monochromatic Mo $\mathrm{K} \alpha$ radiation $(\lambda=0.71073 \AA)$. Single crystals were grown from the corresponding molten solvates in a cooling incubator

$15\left(-10{ }^{\circ} \mathrm{C}\right)$. The single crystals were coated with vacuum grease to prevent contact with air and mounted on a glass pin. The diffraction pattern was measured at $-50{ }^{\circ} \mathrm{C}$ using a steady flow of nitrogen gas stream. An empirical absorption correction was applied to the obtained data using spherical harmonics, imple0 mented in the SCALES3 ABSPACK scaling algorithm (CrysAlisPro 1.171.39.46e, Rigaku Oxford Diffraction, 2018). The crystallographic structure was solved by SHELXT 2018/2 and all non-hydrogen atoms were refined anisotropically by the fullmatrix least-squares method (SHELXL 2018/3). ${ }^{24}$ All the hydrogen atoms were placed in geometrically ideal positions and refined using the riding model.

\section{Results and discussion}

\section{Transport properties}

Simple diketone-based solvents, such as diacetyl and acetyl acetone, were found to be relatively unstable for preparing highly concentrated electrolytes of Li[FSA] in our preliminary tests. Therefore, chemically more stable keto esters were used as the solvents in this study. The keto ester-based highly concentrated electrolytes were prepared by mixing $\mathrm{Li}[\mathrm{FSA}]$ and the solvents (MP, MA, or ML), and the prepared samples remained wholly liquid at room temperature, except for $40 \mathrm{Li}[\mathrm{FSA}]: \mathrm{MP}=1: 0.6$. As with the reported concentrated electrolytes using FSA-based salts, ${ }^{25-28}$ the high Li salt solubility and the glass-forming properties may have their origin in the molecular flexibility of the FSA anions rendering its salts or complexes difficult to crystallize. Table 1 summarizes the ities $(\sigma)$, self-diffusion coefficients of the components $\left(D_{\mathrm{sol}}, D_{\mathrm{Li}}\right.$, and $\left.D_{\mathrm{FSA}}\right)$, and glass transition temperatures $\left(T_{\mathrm{g}}\right)$ of the keto ester-based highly concentrated electrolytes (a $1: 1$ equimolar ratio of $\mathrm{Li}[\mathrm{FSA}]$ and the solvent) at $30{ }^{\circ} \mathrm{C}$. It is not surprising to note in Table 1 that MP- and ML-based electrolytes are relatively viscous liquids with $\eta$ exceeding $1000 \mathrm{mPa}$ s at $30{ }^{\circ} \mathrm{C}$, leading to a relatively low $\sigma$ of $10^{-4} \mathrm{~S} \mathrm{~cm}^{-1}$. The MA-based electrolyte showed a one-order of magnitude lower $\eta$, and higher $\sigma$ and diffusion constants even with its intermediate $c_{\mathrm{Li}}$ and $T_{\mathrm{g}}$. The reason for the exceptionally low viscosity is not clear at present.

More interestingly, either $D_{\mathrm{Li}}$ or $D_{\mathrm{FSA}}$ is the highest among the diffusion constants measured for all the components, suggesting that the ionic species (namely, $\mathrm{Li}^{+}$or $[\mathrm{FSA}]^{-}$) can diffuse faster than the solvent. $\mathrm{Li}^{+}$ions are the most mobile in the MP- and MAbased electrolytes whereas FSA anions diffuse the fastest in MLbased electrolytes. These observations are contrary to the situation in conventional electrolyte solutions. In typical organic liquid electrolytes with $1 \mathrm{~mol} \mathrm{dm}^{-3}$ of Li salt, the self-diffusion coefficients follow the order: $\mathrm{Li}^{+}<$anion $<$solvents. ${ }^{29,30}$ Despite the smallest size of isolated $\mathrm{Li}$ ions, $D_{\mathrm{Li}}$ is smaller than $D_{\text {sol }}$ as a consequence of the larger hydrodynamic radius of the 'solvated' $\mathrm{Li}$ ions, in reference to the Stokes-Einstein relationship.

In our previous work, it was found that the same holds true for highly concentrated, molten complex electrolytes of lithium bis(trifluoromethanesulfonyl)amide (Li[TFSA] $>3 \mathrm{~mol} \mathrm{dm}^{-3}$ ) in tetrahydrofuran (THF), 1,2-dimethoxyethane (DME), and dimethyl sulfoxide (DMSO) where the solvent molecules diffuse faster than the ions. ${ }^{31,32}$ Moreover, a higher diffusion coefficient of water than the component ions of the Li salt and physical diffusion of hydrated $\mathrm{Li}$ ions were also reported for molten salt hydrate electrolytes, determined by diffusivity measurements combined with molecular dynamics simulations. ${ }^{33}$ It should be noted that specific cases have been observed for other molten complexes of Li[TFSA] and multidentate oligoether solvents such as triglyme (G3) and tetraglyme (G4). In the equimolar complexes of Li[TFSA] and G3 or G4 (so-called solvate ionic liquids), $D_{\mathrm{Li}}$ is found to be identical to $D_{\text {sol }}$, indicating that long-lived Li complex ions are formed due to the strongly chelating properties of G3 and G4. ${ }^{32}$ Nevertheless, in the glyme-Li salt solvate ionic liquids, the $\mathrm{Li}$ ion transport can generally be interpreted as being via the physical diffusion mechanism that premises the translational motion of the solvated ions in a similar manner to that for ionic liquids ${ }^{34}$ as well as dilute electrolyte solutions. ${ }^{29}$ In contrast to these examples, the diffusion behavior observed for the highly concentrated $\mathrm{Li}[\mathrm{FSA}] /$ keto ester systems is more akin to our recently published observations for SL-based concentrated electrolytes. ${ }^{19}$

Fig. 2 shows the diffusivity ratios $D_{\mathrm{sol}} / D_{\mathrm{Li}}$ and $D_{\mathrm{FSA}} / \mathrm{D}_{\mathrm{Li}}$ in the concentrated electrolytes with various [solvent]/[Li] ratios. As shown in Fig. 2a, $D_{\mathrm{sol}} / D_{\mathrm{Li}}$ of all the samples was less than unity in the range of [solvent $] /[\mathrm{Li}]$ ratios studied. The lower $D_{\mathrm{sol}} / D_{\mathrm{Li}}$ at a lower [solvent $] /[\mathrm{Li}]$ ratio indicates that the mobility of Li ions

Table 1 Lithium salt concentrations $\left(c_{\mathrm{Li}}\right)$, viscosity $(\eta)$, ionic conductivity $(\sigma)$, self-diffusion coefficient of the components $\left(D_{\text {sol, }} D_{\mathrm{Li}}\right.$, and $\left.D_{\mathrm{FSA}}\right)$, and glass transition temperature $\left(T_{\mathrm{g}}\right)$ of Li[FSA] :MP $=1: 1$, Li[FSA] :MA = 1:1, and Li[FSA] :ML $=1: 1$ at $30{ }^{\circ} \mathrm{C}$

\begin{tabular}{|c|c|c|c|c|c|c|c|}
\hline Molar ratio $1: 1$ & $c_{\mathrm{Li}} \mathrm{mol} \mathrm{dm}^{-3}$ & $\eta \mathrm{mPa} \mathrm{s}$ & $\sigma \mathrm{mS} \mathrm{cm}^{-1}$ & $D_{\text {sol }} \times 10^{-7} \mathrm{~cm}^{2} \mathrm{~s}^{-1}$ & $D_{\mathrm{Li}} \times 10^{-7} \mathrm{~cm}^{2} \mathrm{~s}^{-1}$ & $D_{\mathrm{FSA}} \times 10^{-7} \mathrm{~cm}^{2} \mathrm{~s}^{-1}$ & $T_{\mathrm{g}}{ }^{\circ} \mathrm{C}$ \\
\hline Li[FSA]: MP & 5.58 & 1220 & 0.43 & 0.20 & 0.21 & 0.16 & -43.7 \\
\hline Li[FSA]: MA & 5.08 & 270 & 1.51 & 0.61 & 0.70 & 0.60 & -53.3 \\
\hline Li[FSA]: ML & 4.69 & 1030 & 0.37 & 0.13 & 0.15 & 0.18 & -62.9 \\
\hline
\end{tabular}


(a)

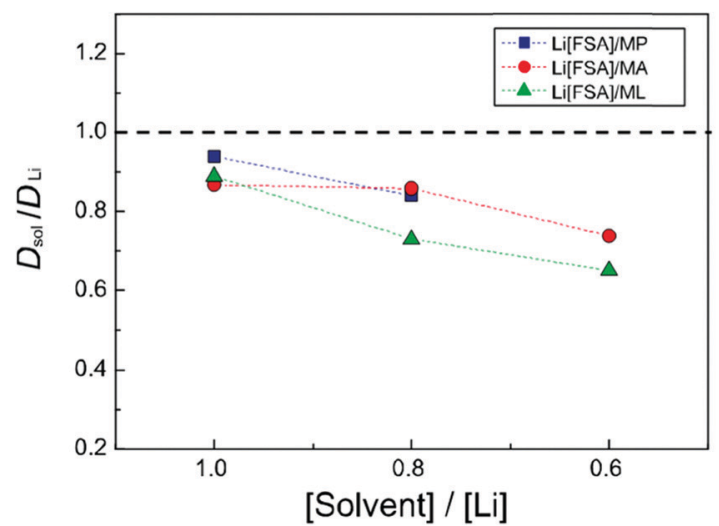

(b)

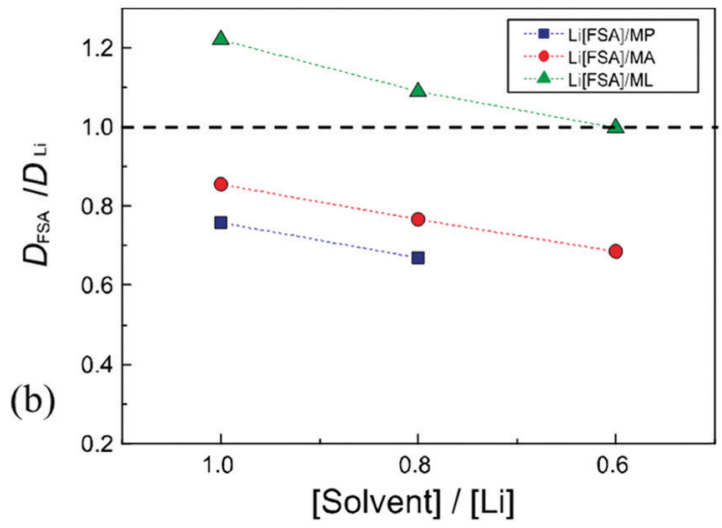

1

5

10

Fig. 2 Diffusivity ratios (a) $D_{\text {sol }} / D_{\mathrm{Li}}$ and (b) $D_{\mathrm{FSA}} / D_{\mathrm{Li}}$ in the keto ester-based concentrated electrolytes of Li[FSA] at $30^{\circ} \mathrm{C}$.

1$$
5
$$

became even greater than that of the solvent molecules. Obviously, the keto ester-based concentrated electrolytes can be considered as exceptional with regard to ionic transport behavior when compared with typical liquid electrolytes. The lower $D_{\mathrm{sol}} / D_{\mathrm{Li}}$ for the ML-based electrolytes is probably attributable to the larger size of the ML molecules. In Fig. $2 \mathrm{~b}, D_{\mathrm{FSA}} / D_{\mathrm{Li}}$ was also less than unity for MP- and MA-based electrolytes and decreased with decreasing [solvent $] /[\mathrm{Li}]$ ratio. The fastest $\mathrm{Li}$ ion transport in these electrolytes cannot be explained by the simple physical diffusion of Li ions because Li ions are unlikely to exist in the 'naked' (unsolvated) form but should be stabilized by coordination by the donor sites of the solvents and counter anions. For ML-based electrolytes, $D_{\mathrm{FSA}} / D_{\mathrm{Li}}$ was greater than unity and the value approached unity at $[$ solvent $] /[\mathrm{Li}]=0.6$, confirming that FSA anions are the fastest diffusive component in the electrolytes. The $\mathrm{Li}$ transference number $\left(t_{\mathrm{Li}}\right)$ estimated by the self-diffusion coefficient of the ions, $t_{\mathrm{Li}}=D_{\mathrm{Li}} /\left(\mathrm{D}_{\mathrm{Li}}+D_{\mathrm{FSA}}\right)$, marked a high value ranging from 0.54 to 0.60 for MP- and MAbased electrolytes, while $t_{\mathrm{Li}}$ was found to be lower than 0.5 for the ML-based electrolytes (see the ESI, $\dagger$ Fig. S1).

The anomalous ionic diffusion behavior in the keto esterbased electrolytes may be attributed to transport mechanisms other than simple physical diffusion. In proton-conducting electrolytes, another mechanism is proposed for proton transport in addition to the physical transport of hydronium ions (known as the vehicle mechanism): the proton-hopping Grotthuss or structural diffusion mechanism, which relies on proton exchange reactions from one site to another through the hydrogen bond network in aqueous electrolytes. ${ }^{35}$ Experimental evidence for ionic diffusion occurring faster than that of the solvents suggests that the ionic transport in keto esterbased electrolytes involves a Li ion hopping/exchange mechanism. Moreover, as shown in Fig. 2b, there is an intriguing difference in the ionic transport behavior between MP- and MAbased electrolytes and ML-based electrolytes despite their structural analogy. The more-pronounced diffusion of Li ions for the former may result from predominant $\mathrm{Li}$ ion hopping or exchange between coordinating sites, which is akin to that observed for SL-based concentrated electrolytes. ${ }^{19}$ In contrast, more frequent anion exchange reactions can be responsible for the fastest diffusion of FSA anions in the latter. We note here that a similar diffusion behavior of FSA anions was also observed in highly concentrated electrolytes comprised of Li[FSA] in G3 or G4 when Li[FSA] was in stoichiometric excess. ${ }^{28}$ It can be conceived that these unusual ionic transport behaviors may correlate with a unique coordination structure in these dense electrolytes since an extended network structure plays an essential role in the proton-hopping Grotthuss-type mechanism. ${ }^{35}$ Therefore, we subsequently studied how the subtle change in the molecular structure of the keto ester solvents affects the $\mathrm{Li}$ ion coordination, towards clarifying the origin of the observed difference in ionic transport behavior between MP- or MA-based electrolytes and ML-based electrolytes.

\section{Coordination structure}

The Li ion coordination structures in the keto ester-based electrolytes were investigated with single X-ray crystallography and Raman spectroscopy with the aid of DFT calculations. For MP-based electrolytes, a single crystalline sample could be obtained at $[\mathrm{MP}] /[\mathrm{Li}]=0.5$ in which the $\mathrm{Li}$ salt concentration is slightly higher than the studied liquid electrolytes, and its crystal structure is shown in Fig. 3 and Fig. S2 (ESI $\dagger$ ). The Li ions are coordinated by a total of four or five oxygen atoms contributed by both MP and the FSA anions. MP molecules adopt a s-cis conformation, and the ketone carbonyl oxygen and the ester carbonyl oxygen atoms bind to different Li ions with a Li-O distance of $\sim 1.95 \AA$. The ketone carbonyl oxygen also interacts with the $\mathrm{Li}$ ion that is coordinated by the ester carbonyl oxygen of the same MP molecules (i.e. as a bidentate ligand), but the Li-O distance is rather long $(\sim 2.53 \AA)$. FSA anions adopt a $\mathrm{C}_{1}$ (cisoid) conformation ${ }^{36}$ and are coordinated to three different Li ions using three of the four oxygen atoms of the two sulfonyl groups, forming polymeric chains, $\mathrm{Li}^{+} \cdots$ FSA $\cdots \mathrm{Li}^{+} \cdots$ FSA $\cdots$. Furthermore, MP molecules and FSA anions form a joint polymeric cluster with the Li ion linkages, i.e. $\cdots \mathrm{MP} \cdots \mathrm{Li}^{+} \cdots \mathrm{FSA} \cdots \mathrm{Li}^{+} \cdots \mathrm{MP} \cdots$.

Fig. 4a shows Raman spectra in the region of $780-900 \mathrm{~cm}^{-1}$ for MP-based liquid electrolytes and solid complexes 
Fig. 3 Ball and stick models for a single crystal of the MP-Li[FSA] solvate at $[\mathrm{MP}] /[\mathrm{Li}]=0.5$. Hydrogen atoms are omitted for clarity. Purple, Li; red, $\mathrm{O}$ gray, C; yellow, S; light green, F; and light blue, N. CCDC 1886677.†

with Li[FSA]. The peaks in the range of $810-880 \mathrm{~cm}^{-1}$ can be assigned to the mixed modes of $\mathrm{C}-\mathrm{C}$ stretching, $\mathrm{CH}_{3}$ rocking and $\mathrm{C}-\mathrm{O}$ stretching vibrations of the methyl ester group, ${ }^{37}$ and were found to be sensitive to $\mathrm{Li}$ salt concentration in our preliminary Raman experiments. By contrast, it was difficult
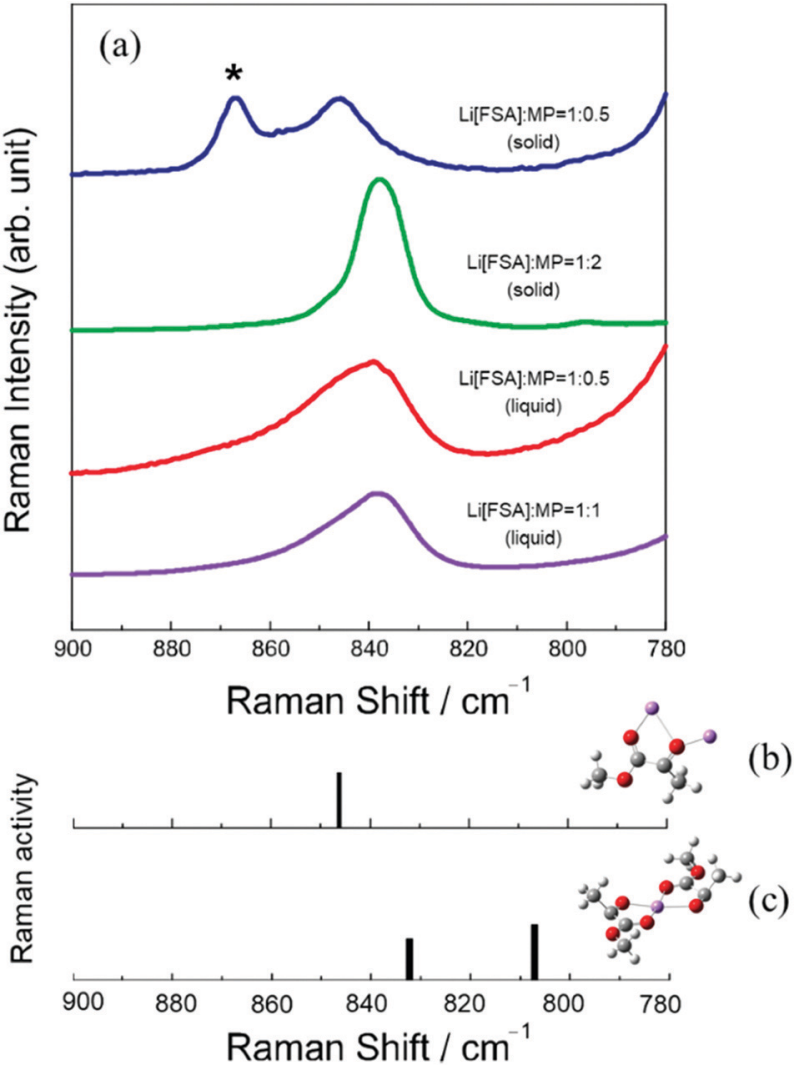

Fig. 4 (a) Raman spectra of MP-based liquid electrolytes ([MP]/[Li] = 1) and solid or supercooled complexes ([MP]/[Li] $=0.5,1$ and 2) with Li[FSA], and theoretical Raman bands of (b) the $\mathrm{Li}^{+}-\mathrm{MP}(2: 1)$ complex extracted from the crystalline structure of the complex at $[\mathrm{MP}] /[\mathrm{Li}]=0.5$ and (c) the $\mathrm{Li}^{+}-\mathrm{MP}(1: 2)$ complex from the roughly refined crystal structure at [MP]/ $[\mathrm{Li}]=2$, in the range of $780-900 \mathrm{~cm}^{-1}$ corresponding to the mixed modes of $\mathrm{C}-\mathrm{C}$ stretching, $\mathrm{CH}_{3}$ rocking and $\mathrm{C}-\mathrm{O}$ stretching vibrations of the methyl ester group of MP. The peak (*) at $868 \mathrm{~cm}^{-1}$ is due to Li[FSA] (solid) contained in the measured sample (see Fig. S4 in the ESI†). to analyze the $\mathrm{C}=\mathrm{O}$ stretching bands of ketone and ester groups (around $1700 \mathrm{~cm}^{-1}$ ) on account of their complicated change and band overlap upon addition of Li salt (Fig. S3, ESI $\dagger$ ). The crystalline solid of $[\mathrm{MP}] /[\mathrm{Li}]=0.5$ exhibits a peak at $846 \mathrm{~cm}^{-1}$, corresponding to the s-cis MP complex coordinated with two Li ions as found in the single crystal structure. This band was well reproduced by the vibrational analysis of the $\mathrm{Li}^{+}-$ MP (2:1) complex extracted from the crystalline structure (Fig. 4b). Another peak at $868 \mathrm{~cm}^{-1}$ was attributed to the additional presence of solid Li[FSA] in the crystalline sample used for collecting experimental Raman spectra (Fig. S4, ESI $\dagger$ ). The MP-based electrolytes formed another solid solvate at [MP]/ $[\mathrm{Li}]=2$, although we could not obtain a reliable crystallographic model with an acceptable $R$-factor. However, the roughly refined model implies that two MP molecules coordinate in a co-planar bidentate manner with one $\mathrm{Li}$ ion, and the $\mathrm{Li}$ ion is further coordinated by an oxygen atom of the FSA anions from the top and bottom sides of the $\left[\mathrm{Li}(\mathrm{MP})_{2}\right]$ plane in the crystalline solvate (Fig. S5, ESI $\dagger$ ). The $\left[\mathrm{Li}(\mathrm{MP})_{2}\right]$ coordination shows a relatively sharp Raman peak (Fig. 4a) at $837 \mathrm{~cm}^{-1}$ with a small peak around $800 \mathrm{~cm}^{-1}$, likely due to the two bidentate MP molecules in the form of the co-planar coordination as suggested by the corresponding theoretical bands at 833 and $807 \mathrm{~cm}^{-1}$ (Fig. 4c). The asymmetric peak around $840 \mathrm{~cm}^{-1}$ for the liquid electrolyte of $[\mathrm{MP}] /[\mathrm{Li}]=1$ can be interpreted as resulting from the sum of the two aforementioned peaks (bridging MP at $846 \mathrm{~cm}^{-1}$ and bidentate MP at $837 \mathrm{~cm}^{-1}$ ) found in the two solid solvates. A similar asymmetric peak was also observed for the molten (supercooled) state at $[\mathrm{MP}] /[\mathrm{Li}]=$ 0.5 with a larger apparent contribution from the peak corresponding to the bridging MP (at $846 \mathrm{~cm}^{-1}$ ). Therefore, MP-bridged ionic aggregates and the $\left[\mathrm{Li}(\mathrm{MP})_{2}\right]$-like coordination are likely to coexist in the MP-based liquid electrolytes in the range of $[\mathrm{MP}] /[\mathrm{Li}]=0.6$ to 1 .

The Raman bands in the range of $720-760 \mathrm{~cm}^{-1}$ correspond to the symmetric stretching vibration of the $\mathrm{S}-\mathrm{N}-\mathrm{S}$ skeleton of FSA anions and have been well studied for Li[FSA]-based electrolytes in organic solvents ${ }^{26,28}$ and ionic liquids. ${ }^{36,38}$ As seen in Fig. 5, the peak continuously shifts from $720 \mathrm{~cm}^{-1}$ to $755 \mathrm{~cm}^{-1}$ with increasing Li salt concentration (i.e., decreasing $[\mathrm{MP}] /[\mathrm{Li}])$ in the MP-based liquid electrolytes. A systematic Raman study of AN/Li[FSA] systems has shown possible assignments of different ionic association states of FSA: 720 to $726 \mathrm{~cm}^{-1}$ for uncoordinated anions, $735 \mathrm{~cm}^{-1}$ for contact ion pairs (CIP), and $741 \mathrm{~cm}^{-1}$ to $752 \mathrm{~cm}^{-1}$ for highly aggregated ion pairs (AGG). ${ }^{26}$ A similar large Raman shift was also reported for $N$-propyl- $N$-methylpyrrolidinium bis(fluorosulfonyl)amide $\left(\left[\mathrm{C}_{3} \mathrm{mpyr}\right][\mathrm{FSA}]\right)$, mixed with $\mathrm{Li}[\mathrm{FSA}]^{38}$ and glyme/Li[FSA] systems. ${ }^{28}$ In these works, the broad Raman peak around 750 $\mathrm{cm}^{-1}$ in the high Li concentration regime was attributed to higher levels of ionic aggregates. Likewise, we can expect that AGG or multiple ionic clusters such as $\mathrm{Li}_{x}[\mathrm{FSA}]_{y}{ }^{(y-x)-}$ were present in MP-based concentrated electrolytes at $[\mathrm{MP}] /[\mathrm{Li}]$ less than 1. As shown in Fig. S6 (ESI $\dagger$ ), the Raman spectra of the MA-based and ML-based electrolytes also showed a similar peak shift from $720 \mathrm{~cm}^{-1}$ to $755 \mathrm{~cm}^{-1}$ with increasing Li salt 


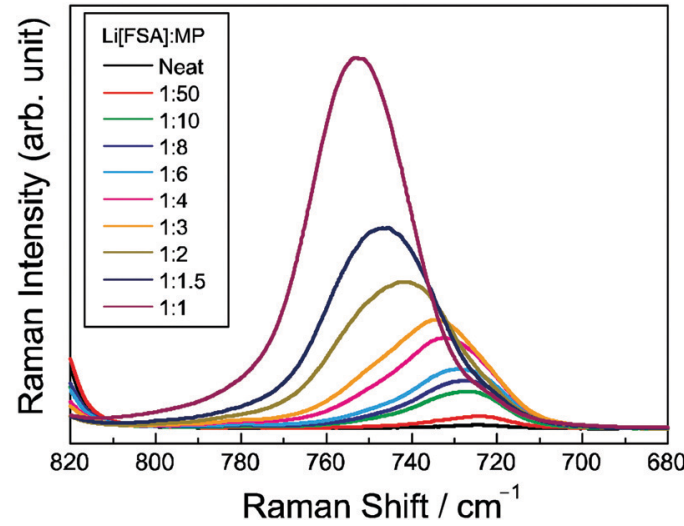

Fig. 5 Raman spectra of MP-based liquid electrolytes at various $\mathrm{Li}[\mathrm{FSA}]$ : MP ratios in the range of $680-820 \mathrm{~cm}^{-1}$ for the symmetric stretching vibration of the $\mathrm{S}-\mathrm{N}-\mathrm{S}$ skeleton of FSA anions.

concentration, and a broad Raman peak around $750 \mathrm{~cm}^{-1}$ in the high Li concentration regime. Therefore, we assume that AGG or ionic clusters are formed in the keto ester-based highly concentrated electrolytes in the studied range of Li salt concentrations.

For MA-based electrolytes, Raman spectra in the region of 1600-1800 $\mathrm{cm}^{-1}$ (for $\mathrm{C}=\mathrm{O}$ stretching) suggested the presence of the enol form in addition to the keto form due to keto-enol tautomerism in neat MA solvent (Fig. S7, ESI $\dagger$ ). ${ }^{39}$ However, the peak at $1627 \mathrm{~cm}^{-1}$ corresponding to the enol form declined with the addition of Li[FSA], and completely vanished at [MA]/ [Li] lower than 2, indicating that MA molecules exist entirely in the keto form in MA-based concentrated electrolytes, consistent with another study indicating the decreasing enol content of a $\beta$-keto ester with increasing alkali metal salt concentration. ${ }^{40}$ Unfortunately, we could not obtain any crystalline solids adequate for X-ray crystallography over the range of $[\mathrm{MA}] /[\mathrm{Li}]$ studied. Instead, replacement of FSA anions by an analog, TFSA, allowed the MA-based electrolytes to form a fine crystal in the concentration region of our interest. Fig. 6 and Fig. S8 (ESI $\dagger$ ) show the single crystal structure of the crystalline solvate at $[\mathrm{MA}] /[\mathrm{Li}]=0.5$ for the MA-Li[TFSA $]$ system. Similar to the MP-Li[FSA $]$ solvate at $[\mathrm{MP}] /[\mathrm{Li}]=0.5$, the ketone carbonyl oxygen and the ester carbonyl oxygen atoms of MA coordinate to different neighboring $\mathrm{Li}$ ions with $\mathrm{Li}-\mathrm{O}$ distances of 1.86-1.91 Å. Again, MA molecules served as a linker to form a solvent-shared, extended ionic network $\cdots \mathrm{MA} \cdot \mathrm{Li}^{+} \cdots \mathrm{TFSA} \cdot \mathrm{Li}^{+} \cdots \mathrm{MA} \cdots$ in the crystal at $[\mathrm{MA}] /[\mathrm{Li}]=0.5$. TFSA anions in the $\mathrm{C}_{1}$ (cisoid) conformation coordinate to three $\mathrm{Li}$ ions. However, in contrast to the crystal structure of $[\mathrm{MP}] /[\mathrm{Li}]=0.5$ (Fig. 3), Li ions coordinated only by TFSA anions are also present, in addition to Li ions coordinated by both MA and TFSA. Furthermore, we found another crystal structure in the same sample at $[\mathrm{MA}] /[\mathrm{Li}]=0.5$ (Fig. S9, ESI $\dagger$ ) in which MA molecules have a little different conformation from that shown in Fig. 6, but form a similar solvent-shared $\mathrm{Li}$ ion coordination structure. These polymorphs of the crystalline solvate at $[\mathrm{MA}] /[\mathrm{Li}]=0.5$ were considered for the following discussion on Raman spectra.

In Fig. 7a, Raman spectra in the region of $770-890 \mathrm{~cm}^{-1}$ for MA-based liquid electrolytes of $\mathrm{Li}[\mathrm{FSA}]([\mathrm{MA}] /[\mathrm{Li}]=1)$ were

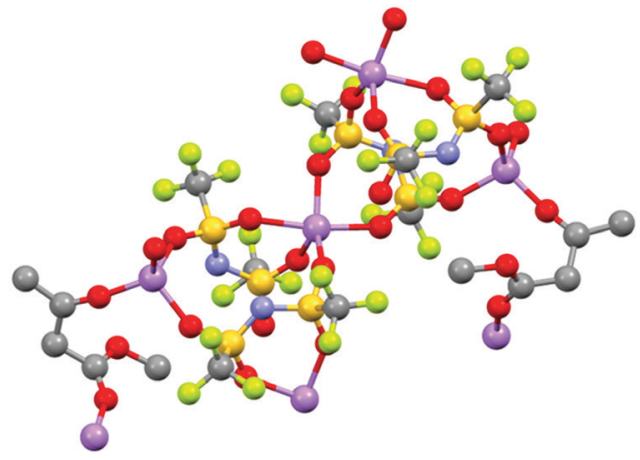

1

Fig. 6 Ball and stick models for a single crystal of the MA-Li[TFSA] solvate at $[\mathrm{MA}] /[\mathrm{Li}]=0.5$. Hydrogen atoms are omitted for clarity. Purple, Li; red, O; gray, C; yellow, S; light green, F; and light blue, N. CCDC 1892798.†

compared with those of the crystalline and molten complexes with $\mathrm{Li}[\mathrm{TFSA}]([\mathrm{MA}] /[\mathrm{Li}]=0.5)$. The peak in the region of $810-$ $890 \mathrm{~cm}^{-1}$ involves the mixed modes of $\mathrm{C}-\mathrm{C}$ stretching, $\mathrm{CH}_{3}$ rocking and $\mathrm{C}-\mathrm{O}$ stretching vibrations of MA molecules, ${ }^{39}$ and is sensitive to the conformational changes in the MA molecule upon $\mathrm{Li}$ coordination. Fig. 7b, c, d and e also show the

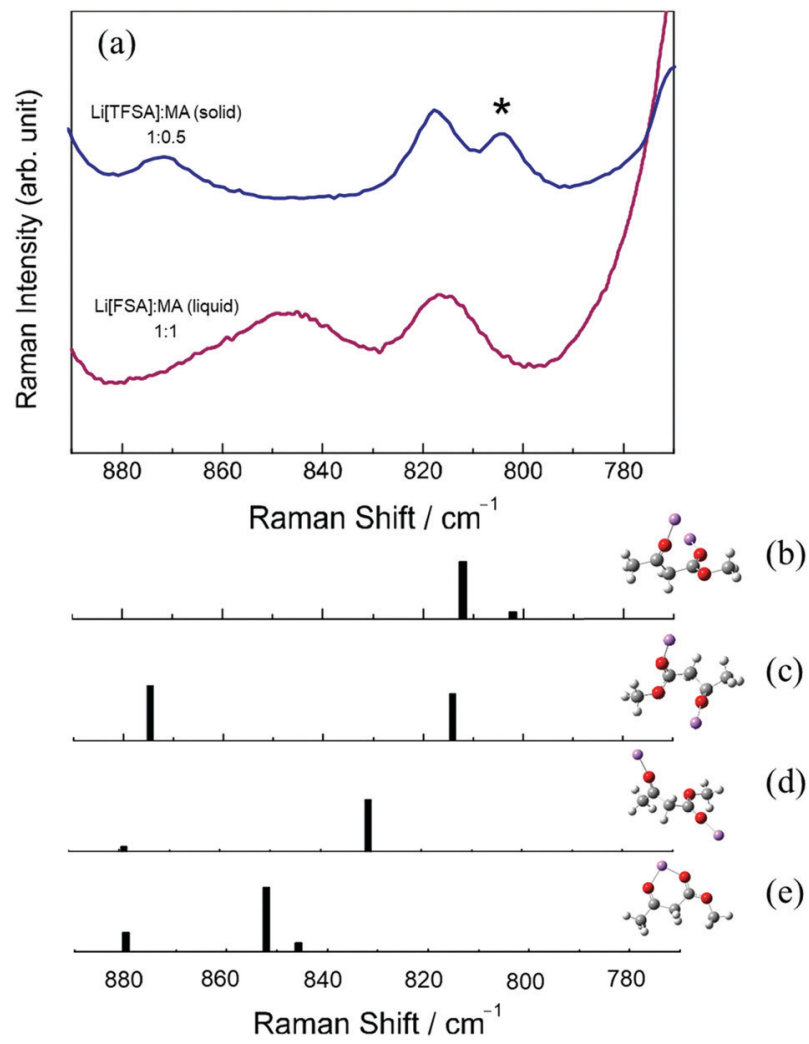

Fig. 7 (a) Raman spectra of MA-based liquid electrolyte $([\mathrm{MA}] /[\mathrm{Li}]=1)$ with Li[FSA] and solid complex ([MA]/[Li] $=0.5)$ with Li[TFSA $]$, and theoretical Raman bands and corresponding structures of the $\mathrm{Li}^{+}-\mathrm{MA}(2: 1)$ complex extracted from the crystal structure (b) Fig. 6 and (c) Fig. S9 (ESI $\dagger$ ). (d) Optimized $\mathrm{Li}^{+}-\mathrm{MA}(2: 1)$ bridging complex and (e) optimized $\mathrm{Li}^{+}-\mathrm{MP}$ $(1: 1)$ bidentate complex, in the range of $770-890 \mathrm{~cm}^{-1}$, corresponding to the mixed modes of $\mathrm{C}-\mathrm{C}$ stretching, $\mathrm{CH}_{3}$ rocking and $\mathrm{C}-\mathrm{O}$ stretching vibrations of MA. The peak $\left(^{*}\right)$ at $806 \mathrm{~cm}^{-1}$ is derived from TFSA anions. 
1 theoretical Raman bands corresponding to possible $\mathrm{Li}$ ion coordination structures in MA-based electrolytes. The Raman band at $806 \mathrm{~cm}^{-1}$ is derived from TFSA anions for the crystalline and molten complexes with Li[TFSA]. The experimental Raman bands of the crystalline complex of $[\mathrm{MA}] /[\mathrm{Li}]=0.5$ agree well with theoretical Raman bands of the $\mathrm{Li}^{+}-\mathrm{MA}(2: 1)$ complex extracted from the crystalline structures at 802 and $813 \mathrm{~cm}^{-1}$ in Fig. 7b, and 814 and $875 \mathrm{~cm}^{-1}$ in Fig. 7c. The theoretical Raman bands at 813 (Fig. 7b) and $814 \mathrm{~cm}^{-1}$ (Fig. 7c) shift to $830 \mathrm{~cm}^{-1}$

10 for the optimized $\mathrm{Li}^{+}-\mathrm{MA}(2: 1)$ complex with the bridging structure (Fig. 7d) and to 846 and $852 \mathrm{~cm}^{-1}$ for the optimized $\mathrm{Li}^{+}$-MA (1:1) complex with the bidentate structure (Fig. 7e). The Raman spectrum of the MA-based liquid electrolyte of $\mathrm{Li}[\mathrm{FSA}]([\mathrm{MA}] /[\mathrm{Li}]=1)$ was somewhat broader, probably due to 5 the presence of different conformations of MA molecules in the liquid state. The broad peaks around 816 and $848 \mathrm{~cm}^{-1}$ indicate that the MA molecules adopt a variety of conformations including both bridging and bidentate structures. As a result, in the MA-based concentrated liquid electrolytes, it is suggested that both MA-bridged and FSA-bridged ionic aggregates would be present in addition to other Li-MA complexes with the bidentate form of MA.

For ML-based concentrated systems, we could not obtain a high-quality crystal adequate for single X-ray crystallography with either Li[FSA] or Li[TFSA]. Fig. 8a shows the concentration dependent Raman spectra in the range of $860-940 \mathrm{~cm}^{-1}$. A characteristic peak corresponding to neat $\mathrm{ML}$ at $896 \mathrm{~cm}^{-1}$, resulting from the mixed modes of $\mathrm{C}-\mathrm{C}$ stretching, $\mathrm{CH}_{3}$ rocking and $\mathrm{C}-\mathrm{O}$ stretching vibrations, was well reproduced by the DFT 0 calculation (Fig. 8b). With increasing salt concentration, the intensity of the peak at $897 \mathrm{~cm}^{-1}$ for neat ML decreased, but two peaks emerged at 870 and $910 \mathrm{~cm}^{-1}$ and their intensity increased. As seen in Fig. 8c, these peaks at 870 and $910 \mathrm{~cm}^{-1}$ correspond to the bidentate form of the $\mathrm{Li}^{+}-\mathrm{ML}(1: 1)$ complex. 5 The DFT calculation predicted that the bridged $\mathrm{Li}^{+}-\mathrm{ML}(2: 1)$ complex shows a Raman band at $896 \mathrm{~cm}^{-1}$ (Fig. 8d), which is close to that of neat ML. In the experimental Raman spectrum for the ML-based concentrated electrolyte $(1: 1)$, the intensity around 890-900 $\mathrm{cm}^{-1}$ was very low, implying that both non0 coordinating and bridging ML may be unlikely to exist or their fraction is very small: most of the ML molecules would adopt the bidentate form in ML-based concentrated electrolytes. It is likely that $\mathrm{ML}$, with a greater intramolecular distance between the carboxyl groups, prefers to conformationally adopt

45 a bidentate structure for coordinating to Li ions. A similar scenario can be derived from the Raman spectra in the range of $700-810 \mathrm{~cm}^{-1}$ (Fig. S10, ESI $\dagger$ ). The Raman band at $767 \mathrm{~cm}^{-1}$ for neat ML decreases, and the band at $779 \mathrm{~cm}^{-1}$ for the bidentate ML was intensified with salt concentration. Again, coordinating (767 $\left.\mathrm{cm}^{-1}\right)$ and bridging $\left(765 \mathrm{~cm}^{-1}\right)$ species constitute only small fractions, and therefore the majority of ML may be present in the form of bidentate complexes. As suggested by the Raman band shift for FSA anions (Fig. S6, ESI $\dagger$ ), Li ions and FSA anions formed AGG or ionic clusters in the ML-based concentrated electrolytes.

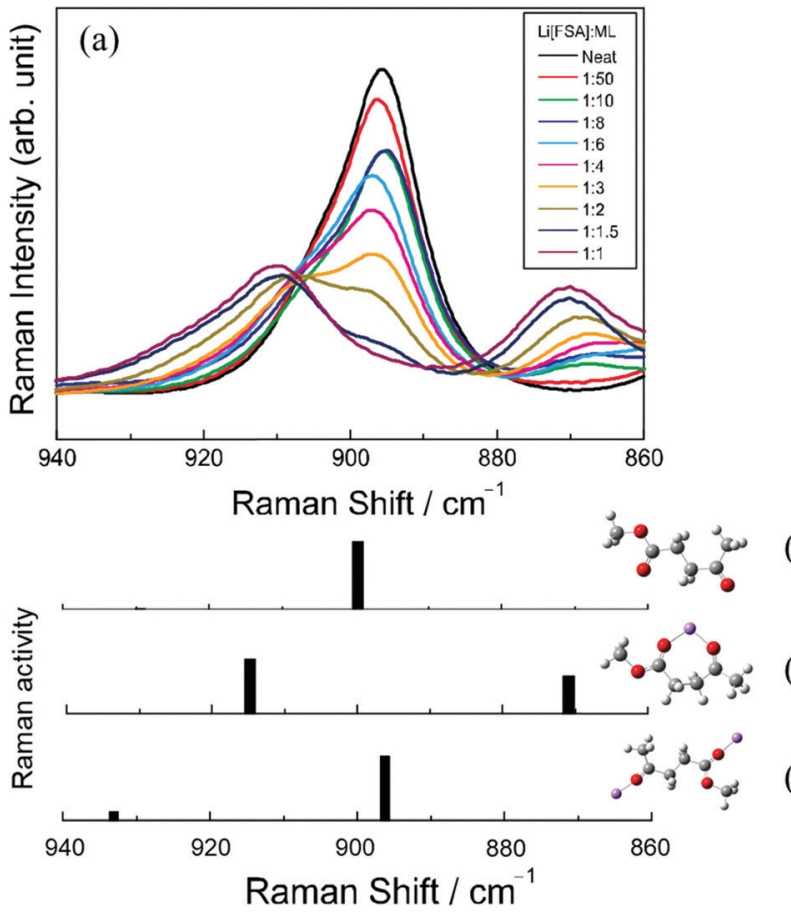

Fig. 8 (a) Raman spectra of ML-based electrolytes at various Li[FSA] : ML ratios and calculated Raman bands of optimized structures for (b) neat $M L$, (c) bidentate $\mathrm{Li}^{+}-\mathrm{ML}(1: 1)$, and (d) bridging $\mathrm{Li}^{+}-\mathrm{ML}(2: 1)$, in the range of 860-940 $\mathrm{cm}^{-1}$ corresponding to the mixed modes of $\mathrm{C}-\mathrm{C}$ stretching, $\mathrm{CH}_{3}$ rocking and $\mathrm{C}-\mathrm{O}$ stretching vibrations of $\mathrm{ML}$.

\section{Correlation between ion transport and the coordination} structure

Given the ionic diffusion behavior and $\mathrm{Li}$ ion coordination structure mentioned in the above sections, there seems to be a clear correlation between them. In MP- and MA-based concentrated electrolytes, for which $\mathrm{Li}^{+}$showed the highest $D$ values among the diffusive components, the presence of solventshared, extended chain-like structures, where solvent molecules coordinate to two different Li ions, was strongly suggested by the single crystal structure of the model systems and the related Raman studies. FSA anions also participated in forming AGG or multi-ionic clusters with Li ions. These experimental findings are very similar to those for SL-based concentrated electrolytes: the fastest $\mathrm{Li}$ ion diffusion and the coexistence of a SL-bridged chain-like structure and the anion-based AGG structure with Li ions. ${ }^{19}$ It is likely that, in AGG structures, Li ions and counter anions are transported both via an ion exchange mechanism and via a simple physical diffusion mechanism. In addition to these processes, Li ion transport can be further enhanced by a Li ion exchange mechanism through solventshared, extended chain-like structures, and this can be the cause of the most pronounced diffusion for Li ions relative to the solvent and anions in these concentrated electrolytes.

In ML-based concentrated electrolytes, the anion-based AGGs were found to be similar to the other keto ester-based concentrated electrolytes. However, the appearance of the solvent bridged structure was less-pronounced because the 
1 bidentate ML apparently accounts for a large proportion of $\mathrm{Li}$ ion coordination. In this case, FSA anions were the fastest diffusive component. These behaviors are notably similar to those for the previously studied G3- and G4-based concentrated electrolytes of $\mathrm{Li}[\mathrm{FSA}]$ with a [glyme]/[Li] ratio lower than 1 . For example, $D_{\mathrm{FSA}}$ was 5.6 times higher than $D_{\mathrm{Li}}$ at $[\mathrm{G} 4] /[\mathrm{Li}]=0.5$, and all the G4 molecules formed crown-ether like [Li(G4)] $]^{+}$ (1:1) complex cations, but no G4-based extended structure was found. The excess Li ions in G3- and G4-based concentrated electrolytes formed similar AGG structures with FSA anions. $^{28}$ In these systems, the multi-dentate solvents coordinating to one Li ion may terminate the ionic chain-like structures based on either ML or FSA with Li ions, leading to lesspronounced solvent bridged structures. Although Li ions and anions can be equally transported through the ion exchange mechanism in AGG structures, an additional Li ion exchange mechanism is unlikely due to the lack of the solvent-shared, extended structures. Rather, Li ions are more prone to diffusion via a vehicle-type mechanism in the form of complex cations with multi-dentate solvents. Since PFG-NMR detects the averaged diffusion coefficient, the vehicle-type diffusion of larger $\mathrm{Li}$ complex ions contributes to the decrease in $D_{\mathrm{Li}}$, and thereby $D_{\text {FSA }}$ was shown to be higher than $D_{\mathrm{Li}}$ in ML- and glyme-based concentrated electrolytes.

\section{Conclusions}

To clarify the key factors behind the Li ion hopping or exchange mechanism in liquid electrolytes, the correlation between ionic diffusion behavior and $\mathrm{Li}$ ion coordination was studied in keto ester-based concentrated electrolytes. Diffusivity measurements by PFG-NMR indicated that Li ions are the fastest among the components in MP- and MA-based concentrated electrolytes whereas FSA anions are the fastest in the corresponding MLbased solutions. These results are indicative of the contribution of a Li ion hopping/exchange mechanism to the ion transport in the keto ester-based concentrated electrolytes. Studies on the single crystal structure and Raman spectra of the related Licomplexes sugoested that a solvent-bridged, chain-like Li ion coordination and AGG of Li ions and FSA anions coexist in MP- and MA-based electrolytes, whereas the solvent-bridged structure is less-pronounced and AGG is present as a predominant ionic network in ML-based electrolytes. Which ionic presence or absence of the solvent-bridged, chain-like $\mathrm{Li}$ ion coordination. The Li ion hopping/exchange dominated transport can be attributed to liquid electrolytes with both the solvent-bridged, chain-like Li ion coordination and AGG or ionic clusters although these considerations need to be verified by further MD simulations in the future. The extent to which the observed Li ion hopping diffusion in the bulk electrolytes affect the actual Li ion flux in the presence of an electric field and concentration gradient in an electrochemical device is not yet understood in detail. However, the significance of the labile Li ion coordination network with the solvent bridging and its correlation with $\mathrm{Li}$ ion hopping diffusion found in this work provides an insight into the design of superionic liquid electrolytes in which Li ion transport can be decoupled from viscositydominated diffusion processes.

\section{Conflicts of interest}

There are no conflicts to declare.

\section{Acknowledgements}

This study was supported in part by the JSPS KAKENHI (Grant No. $16 \mathrm{H} 06053$ to K. U., 18 K14310 to T. M., $18 \mathrm{H} 03926$ to K. D. and $15 \mathrm{H} 05758$ to $\mathrm{M}$. W.) from the Japan Society for the Promotion of Science (JSPS), and the Advanced Low Carbon Technology Research and Development Program (ALCA) of the Japan Science and Technology Agency (JST). The authors wish to acknowledge Prof. Yoshitaka Yamaguchi and Dr Yutaro Kamei for their helpful comments on X-ray crystallography.

\section{References}

1 N. Kamaya, K. Homma, Y. Yamakawa, M. Hirayama, R. Kanno, M. Yonemura, T. Kamiyama, Y. Kato, S. Hama, K. Kawamoto and A. Mitsui, Nat. Mater., 2011, 10, 682-686. 2 Y. Seino, T. Ota, K. Takada, A. Hayashi and M. Tatsumisago, Energy Environ. Sci., 2014, 7, 627-631.

3 Y. Kato, S. Hori, T. Saito, K. Suzuki, M. Hirayama, A. Mitsui, M. Yonemura, H. Iba and R. Kanno, Nat. Energy, 2016, 1, 7.

4 Y. Yamada and A. Yamada, J. Electrochem. Soc., 2015, 162, A2406-A2423.

5 D. W. McOwen, D. M. Seo, O. Borodin, J. Vatamanu, P. D. Boyle and W. A. Henderson, Energy Environ. Sci., 2014, 7, 416-426.

6 K. Yoshida, M. Nakamura, Y. Kazue, N. Tachikawa, S. Tsuzuki, S. Seki, K. Dokko and M. Watanabe, J. Am. Chem. Soc., 2011, 133, 13121-13129.

7 Y. Yamada, K. Furukawa, K. Sodeyama, K. Kikuchi, M. Yaegashi, Y. Tateyama and A. Yamada, J. Am. Chem. Soc., 2014, 136, 5039-5046.

8 Y. Yamada, M. Yaegashi, T. Abe and A. Yamada, Chem. Commun., 2013, 49, 11194-11196.

9 J. Wang, Y. Yamada, K. Sodeyama, C. H. Chiang, Y. Tateyama and A. Yamada, Nat. Commun., 2016, 7, 12032.

10 J. Qian, W. A. Henderson, W. Xu, P. Bhattacharya, M. Engelhard, O. Borodin and J.-G. Zhang, Nat. Commun., 2015, 6, 6362 .

11 R. Petibon, C. P. Aiken, L. Ma, D. Xiong and J. R. Dahn, Electrochim. Acta, 2015, 154, 287-293.

12 L. Suo, W. Xue, M. Gobet, S. G. Greenbaum, C. Wang, Y. Chen, W. Yang, Y. Li and J. Li, Proc. Natl. Acad. Sci. U. S. A., 2018, 115, 1156-1161.

13 D. M. Seo, O. Borodin, D. Balogh, M. O'Connell, Q. Ly, S.-D. Han, S. Passerini and W. A. Henderson, J. Electrochem. Soc., 2013, 160, A1061-A1070. 
114 O. Borodin, G. A. Giffin, A. Moretti, J. B. Haskins, J. W. Lawson, W. A. Henderson and S. Passerini, J. Phys. Chem. C, 2018, 122, 20108-20121.

15 M. Callsen, K. Sodeyama, Z. Futera, Y. Tateyama and I. Hamada, J. Phys. Chem. B, 2017, 121, 180-188.

16 M. Forsyth, H. Yoon, F. Chen, H. Zhu, D. R. MacFarlane, M. Armand and P. C. Howlett, J. Phys. Chem. C, 2016, 120, 4276-4286.

17 M. Brinkkotter, G. A. Giffin, A. Moretti, S. Jeong, S. Passerini and M. Schonhoff, Chem. Commun., 2018, 54, 4278-4281.

18 H. Yoon, P. C. Howlett, A. S. Best, M. Forsyth and D. R. MacFarlane, J. Electrochem. Soc., 2013, 160, A1629-A1637.

19 K. Dokko, D. Watanabe, Y. Ugata, M. L. Thomas, S. Tsuzuki, W. Shinoda, K. Hashimoto, K. Ueno, Y. Umebayashi and M. Watanabe, J. Phys. Chem. B, 2018, 122, 10736-10745.

20 J. Alvarado, M. A. Schroeder, M. Zhang, O. Borodin, E. Gobrogge, M. Olguin, M. S. Ding, M. Gobet, S. Greenbaum, Y. S. Meng and K. Xu, Mater. Today, 2018, 21, 341-353.

21 C. S. Johnson, Prog. Nucl. Magn. Reson. Spectrosc., 1999, 34, 203-256.

22 D. Sinnaeve, Concept Magn. Reson. A, 2012, 40A, 39-65.

23 M. J. Frisch, G. W. Trucks, H. B. Schlegel, G. E. Scuseria, M. A. Robb, J. R. Cheeseman, G. Scalmani, V. Barone, B. Mennucci, G. A. Petersson, H. Nakatsuji, M. Caricato, X. Li, H. P. Hratchian, A. F. Izmaylov, J. Bloino, G. Zheng, J. L. Sonnenberg, M. Hada, M. Ehara, K. Toyota, R. Fukuda, J. Hasegawa, M. Ishida, T. Nakajima, Y. Honda, O. Kitao, H. Nakai, T. Vreven, J. A. Montgomery, J. E. Peralta, F. Ogliaro, M. Bearpark, J. J. Heyd, E. Brothers, K. N. Kudin, V. N. Staroverov, R. Kobayashi, J. Normand, K. Raghavachari, A. Rendell, J. C. Burant, S. S. Iyengar, J. Tomasi, M. Cossi, N. Rega, J. M. Millam, M. Klene, J. E. Knox, J. B. Cross, V. Bakken, C. Adamo, J. Jaramillo, R. Gomperts, R. E. Stratmann, O. Yazyev, A. J. Austin, R. Cammi, C. Pomelli, J. W. Ochterski, R. L. Martin, K. Morokuma, V. G. Zakrzewski, G. A. Voth, P. Salvador, J. J. Dannenberg, S. Dapprich, A. D. Daniels, Farkas, J. B. Foresman, J. V. Ortiz, J. Cioslowski and D. J. Fox, 2009, , DOI: citeulike-article-id:9096580.

24 O. V. Dolomanov, L. J. Bourhis, R. J. Gildea, J. A. K. Howard and H. Puschmann, J. Appl. Crystallogr., 2009, 42, 339-341.
25 J. Lee, Y. Lee, J. Lee, S.-M. Lee, J.-H. Choi, H. Kim, M.S. Kwon, K. Kang, K. T. Lee and N.-S. Choi, ACS Appl. Mater. Interfaces, 2017, 9, 3723-3732.

26 S.-D. Han, O. Borodin, D. M. Seo, Z.-B. Zhou and W. A. Henderson, J. Electrochem. Soc., 2014, 161, A2042-A2053.

27 S. Terada, H. Susa, S. Tsuzuki, T. Mandai, K. Ueno, K. Dokko and M. Watanabe, J. Phys. Chem. C, 2018, 122, 16589-16599.

28 S. Terada, K. Ikeda, K. Ueno, K. Dokko and M. Watanabe, Aust. J. Chem., 2018, DOI: 10.1071/CH18270.

29 K. Hayamizu, Y. Aihara, S. Arai and C. G. Martinez, J. Phys. Chem. B, 1999, 103, 519-524.

30 C. Capiglia, Y. Saito, H. Kageyama, P. Mustarelli, T. Iwamoto, T. Tabuchi and H. Tukamoto, J. Power Sources, 1999, 81, 859-862.

31 R. Tatara, D. G. Kwabi, T. P. Batcho, M. Tulodziecki, K. Watanabe, H.-M. Kwon, M. L. Thomas, K. Ueno, C. V. Thompson, K. Dokko, Y. Shao-Horn and M. Watanabe, J. Phys. Chem. C, 2017, 121, 9162-9172.

32 C. Zhang, K. Ueno, A. Yamazaki, K. Yoshida, H. Moon, T. Mandai, Y. Umebayashi, K. Dokko and M. Watanabe, J. Phys. Chem. B, 2014, 118, 5144-5153.

33 O. Borodin, L. Suo, M. Gobet, X. Ren, F. Wang, A. Faraone, J. Peng, M. Olguin, M. Schroeder, M. S. Ding, E. Gobrogge, A. von Wald Cresce, S. Munoz, J. A. Dura, S. Greenbaum, C. Wang and K. Xu, ACS Nano, 2017, 11, 10462-10471.

34 C. J. Jafta, C. Bridges, L. Haupt, C. Do, P. Sippel, M. J. Cochran, S. Krohns, M. Ohl, A. Loidl, E. Mamontov, P. Lunkenheimer, S. Dai and X. G. Sun, ChemSusChem, 2018, 11, 3512-3523.

35 K.-D. Kreuer, Chem. Mater., 1996, 8, 610-641.

36 K. Fujii, H. Hamano, H. Doi, X. Song, S. Tsuzuki, K. Hayamizu, S. Seki, Y. Kameda, K. Dokko, M. Watanabe and Y. Umebayashi, J. Phys. Chem. C, 2013, 117, 19314-19324.

37 J. Wilmshurst and J. Horwood, Aust. J. Chem., 1971, 24, 1183-1191.

38 H. Yoon, A. S. Best, M. Forsyth, D. R. MacFarlane and P. C. Howlett, Phys. Chem. Chem. Phys., 2015, 17, 4656-4663.

39 M. M. Schiavoni, H. E. Di Loreto, A. Hermann, H.-G. Mack, S. E. Ulic and C. O. Della Védova, J. Raman Spectrosc., 2001, 32, 319-329.

40 Y. Pocker and G. T. Spyridis, J. Am. Chem. Soc., 2002, 124, 10373-10380. 